\title{
MEASUREMENT OF ARTERIAL AGING IN HYPERTENSIVE PATIENTS *
}

\author{
By FRANCOIS M. ABBOUD $†$ AND JOHN H. HUSTON \\ (From the Cardiovascular Section, Department of Internal Medicine, Marquette University \\ School of Medicine and Milwankee County Hospital, Milwankee, Wis.)
}

(Submitted for publication April 3, 1961 ; accepted June 16, 1961)

Roach and Burton (1) described two important changes in arterial walls with advancing age. One is an increase in collagenous fibers causing loss of distensibility with increase in the slope $\mathrm{dP} /$ $\mathrm{dV}$ of arterial pressure-volume curves. The other is a decrease in the unstretched length of these collagenous fibers as the "slack" in them is taken up, possibly by cross linkages and adhesions. This change results in a more rapid decrease in distensibility with stretch and an increase in the rate of change in slope (or the curvature) of pressure-volume curves toward the pressure axis.

An indirect clinical index of the latter effect of aging on arterial walls has been described $(2,3)$ and referred to, arbitrarily, as an "index of arterial rigidity." It does not measure the slope $\mathrm{dP} / \mathrm{dV}$ of arterial pressure-volume curves but the rate of change in slope (or the curvature) with pressure. Thus, it is not directly related to distensibility of the large arteries but it represents the differential of their stiffness with respect to pressure.

Conway and Smith (2) applied this test to a study of "aging of arteries in relation to hypertension" and found that the rigidity indices of older hypertensive patients exceeded those of a control group of 16 young medical students. Their observations $(2,4)$ supported the hypothesis (5) that in the majority of patients with essential hypertension the elevated diastolic pressure is the consequence of aging of arteries. More recently (3) we demonstrated a strong correlation between this index and age which made us suspect that a number of the hypertensives in their studies might be considered to have normal rigidity indices when compared with normal subjects of the same age. Knowing the variation of this index

\footnotetext{
* Supported by a research grant from the Wisconsin Heart Association.

$\dagger$ Work done during the tenure of an American Heart Association Research Fellowship. Present address: Cardiovascular Research Laboratories, College of Medicine, State University of Iowa, Iowa City, Iowa.
}

with physiological aging, we could interpret more correctly the results of the test in hypertensive patients of all age groups. This report presents our results in 100 hypertensive patients. The foregoing hypothesis concerning the etiology of hypertension is re-evaluated.

\section{MATERIAL AND METHOD}

The patients for this investigation came from the wards and outpatient clinic of Milwaukee County Hospital. One hundred ambulatory hypertensive subjects, ranging from 18 to 84 years of age, were studied. Their selection was based on the level of arterial blood pressure without knowledge of the etiology, duration or complications of the hypertension. Neither the reason for their hospitalization nor the presence of any associated disease was known to us. All had a diastolic blood pressure of $110 \mathrm{~mm} \mathrm{Hg}$ or more, but with most patients taking antihypertensive medications, the majority of the blood pressures recorded at the time of the study were only slightly elevated (Table I).

The arterial rigidity index was measured in all the patients. The method required the measurement of intraarterial blood pressure changes resulting from the inhalation of amyl nitrite before the onset of reflex tachycardia. The ratio of the change in pulse pressure $\times 100$ to the related decrease in diastolic pressure during this period is the index of arterial rigidity (Figure 1). A detailed protocol of the test procedure has been presented (3). A complete physical examination and a careful review of the clinical record followed the performance of the test in each patient. The indices were calculated without access to the clinical findings.

The subjects were separated into two groups: those who had normal indices for their age and those who had prematurely high indices. The upper limit of normal for each age was obtained by adding 2 standard deviations to the regression equation: index $=(2.19 \times$ age $)-53.84 \pm$ 16.16 SD. This equation was determined from our study (3) of the effect of age on the arterial rigidity index and was effective in separating the rigidity of aging from that of premature arteriosclerosis. Observations on the clinical characteristics of the two groups of patients were made in an attempt to re-evaluate the relation between hypertension and arteriosclerosis. Probability values were obtained by Student's $t$-distribution and the chisquare test (6). 
RESULTS

Seventy-one hypertensive patients had normal rigidity indices for their age and 29 had indices that were higher than normal (Figure 2). Table
I shows some clinical characteristics of each patient.

Seventy-one hypertensive subjects with normal rigidity indices. The average age of this group

TABLE I

Individual clinical observations on 100 hypertensive patients classified according to their arterial rigidity indices*

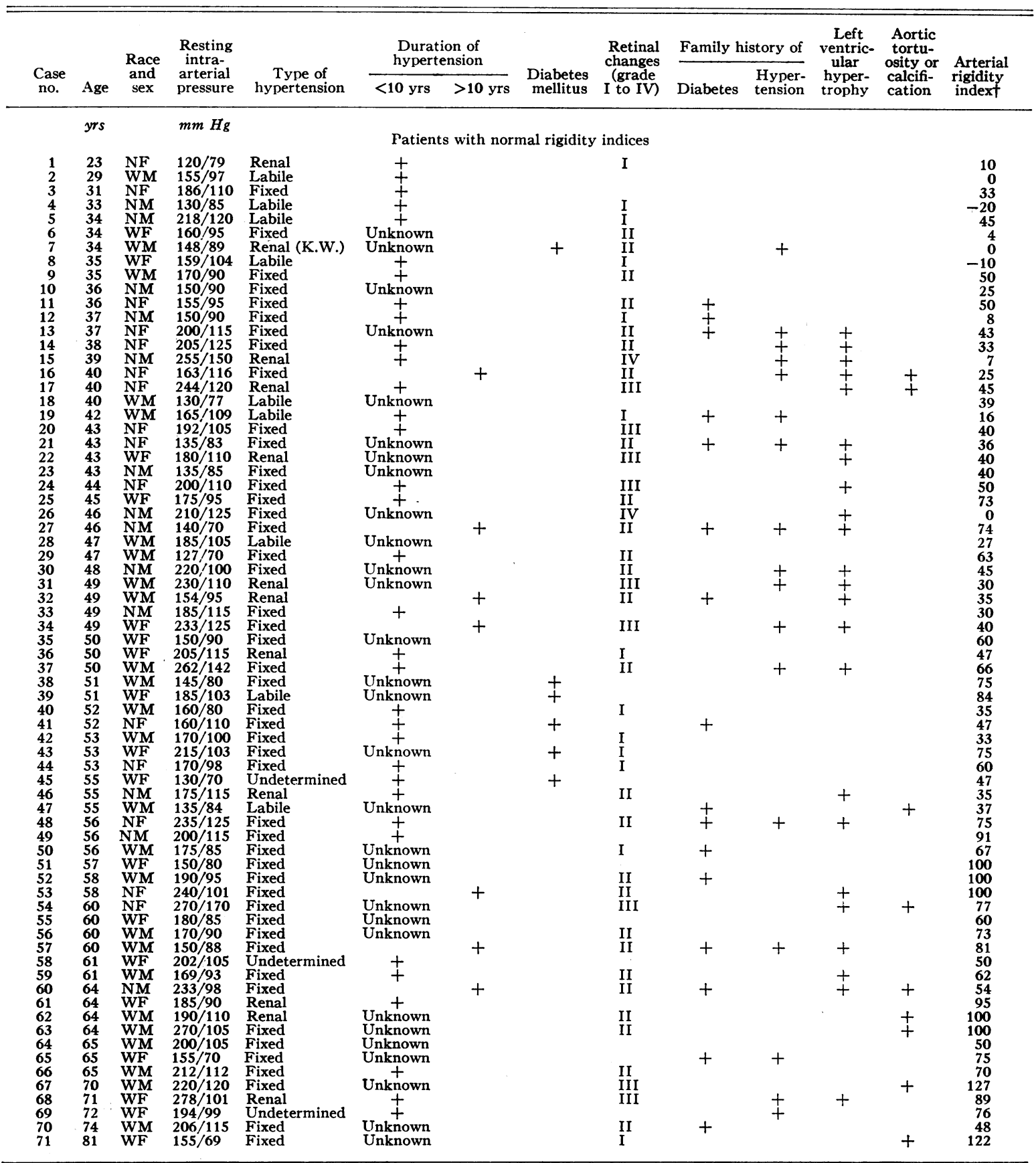

* Abbreviations: $\mathrm{N}=$ =negro; $\mathrm{W}=$ white; $\mathrm{M}=$ male; $\mathrm{F}=$ female; $\mathrm{K} . \mathrm{W} .=$ Kimmelstiel-Wilson's syndrome.

t The upper limit of normal at each age is shown in Figure 2. 


\begin{tabular}{|c|c|c|c|c|c|c|c|c|c|c|c|c|c|}
\hline \multirow{2}{*}{$\begin{array}{l}\text { Case } \\
\text { no. }\end{array}$} & \multirow[b]{2}{*}{ Age } & \multirow{2}{*}{$\begin{array}{l}\text { Race } \\
\text { and } \\
\text { sex }\end{array}$} & \multirow{2}{*}{$\begin{array}{c}\text { Resting } \\
\text { intra- } \\
\text { arterial } \\
\text { pressure }\end{array}$} & \multirow{2}{*}{$\begin{array}{c}\text { Type of } \\
\text { hypertension }\end{array}$} & \multicolumn{2}{|c|}{$\begin{array}{c}\text { Duration of } \\
\text { hypertension }\end{array}$} & \multirow[b]{2}{*}{$\begin{array}{c}\text { Diabetes } \\
\text { mellitus }\end{array}$} & \multirow{2}{*}{$\begin{array}{c}\text { Retinal } \\
\text { changes } \\
\text { (grade } \\
\text { I to IV) }\end{array}$} & \multicolumn{2}{|c|}{ Family history of } & \multirow{2}{*}{$\begin{array}{c}\text { Left } \\
\text { ventric- } \\
\text { ular } \\
\text { hyper- } \\
\text { trophy }\end{array}$} & \multirow{2}{*}{$\begin{array}{l}\text { Aortic } \\
\text { tortu- } \\
\text { osity or } \\
\text { calcifi- } \\
\text { cation }\end{array}$} & \multirow{2}{*}{$\begin{array}{c}\text { Arterial } \\
\text { rigidity } \\
\text { index }\end{array}$} \\
\hline & & & & & $<10$ yrs & $>10 \mathrm{yrs}$ & & & Diabetes & $\begin{array}{l}\text { Hyper- } \\
\text { tension }\end{array}$ & & & \\
\hline & yrs & & $m m \mathrm{Hg}$ & & \multicolumn{9}{|c|}{ Patients with prematurely elevated indices } \\
\hline $\begin{array}{r}1 \\
2 \\
3 \\
4 \\
5 \\
6 \\
7 \\
8 \\
9 \\
10 \\
11 \\
12 \\
13 \\
14 \\
15 \\
16 \\
17 \\
18 \\
19 \\
20 \\
21 \\
22 \\
23 \\
24 \\
25 \\
27 \\
28 \\
29\end{array}$ & $\begin{array}{l}18 \\
29 \\
30 \\
31 \\
41 \\
41 \\
44 \\
46 \\
46 \\
46 \\
46 \\
48 \\
48 \\
49 \\
50 \\
50 \\
52 \\
52 \\
55 \\
56 \\
58 \\
59 \\
59 \\
63 \\
70 \\
80 \\
83 \\
84 \\
84\end{array}$ & $\begin{array}{l}\text { WF } \\
W F \\
\text { NM } \\
W F \\
W F \\
W M \\
W M \\
W F \\
W M \\
W F \\
W M \\
W M \\
W F \\
W F \\
W M \\
W F \\
W M \\
W F \\
W F \\
W F \\
W F \\
W F \\
W F \\
W F \\
W M \\
W F \\
W M \\
W F \\
W F \\
W F\end{array}$ & $\begin{array}{l}160 / 110 \\
141 / 81 \\
154 / 83 \\
175 / 115 \\
233 / 119 \\
195 / 100 \\
152 / 90 \\
190 / 95 \\
190 / 95 \\
155 / 90 \\
210 / 90 \\
265 / 110 \\
176 / 86 \\
190 / 100 \\
218 / 108 \\
141 / 53 \\
118 / 55 \\
180 / 85 \\
200 / 70 \\
191 / 86 \\
195 / 90 \\
200 / 110 \\
180 / 80 \\
240 / 120 \\
220 / 90 \\
210 / 75 \\
215 / 85 \\
180 / 50 \\
210 / 80\end{array}$ & $\begin{array}{l}\text { Labile } \\
\text { Fixed } \\
\text { Renal (K.W.) } \\
\text { Labile } \\
\text { Fixed } \\
\text { Renal (K.W.) } \\
\text { Renal } \\
\text { Fixed } \\
\text { Renal (K.W.) } \\
\text { Labile } \\
\text { Fixed } \\
\text { Renal (K.W.) } \\
\text { Undetermined } \\
\text { Fixed } \\
\text { Fixed } \\
\text { Fixed } \\
\text { Fixed } \\
\text { Fixed } \\
\text { Renal } \\
\text { Fixed } \\
\text { Fixed } \\
\text { Fixed } \\
\text { Renal (K.W.) } \\
\text { Fixed } \\
\text { Renal } \\
\text { Fixed } \\
\text { Fixed } \\
\text { Fixed } \\
\text { Fixed }\end{array}$ & $\begin{array}{c}+ \\
+ \\
+ \\
+ \\
\text { Unknown } \\
\text { Unknown } \\
\text { Unknown } \\
\text { Unknown } \\
+ \\
\text { Unknown } \\
\text { Unknown } \\
\text { Unknown } \\
\\
+ \\
\text { Unknown }\end{array}$ & $\begin{array}{l}+ \\
+ \\
+ \\
+\end{array}$ & $\begin{array}{l}+ \\
+ \\
+\end{array}$ & $\begin{array}{l}\text { I } \\
\text { II } \\
\text { III } \\
\text { II } \\
\text { II } \\
\text { II } \\
\text { II } \\
\text { III } \\
\text { III } \\
\text { I } \\
\text { III } \\
\text { III } \\
\text { II } \\
\text { III } \\
\text { II } \\
\text { II } \\
\text { II } \\
\text { IV } \\
\text { II } \\
\text { II } \\
\text { II } \\
\text { II }\end{array}$ & + & + & $\begin{array}{l}+ \\
+ \\
+ \\
+ \\
+ \\
+ \\
+ \\
+\end{array}$ & $\begin{array}{l}+ \\
+ \\
+ \\
+\end{array}$ & $\begin{array}{r}42 \\
78 \\
53 \\
84 \\
127 \\
82 \\
83 \\
100 \\
82 \\
100 \\
105 \\
136 \\
118 \\
105 \\
108 \\
120 \\
100 \\
105 \\
130 \\
135 \\
143 \\
180 \\
200 \\
160 \\
173 \\
1168 \\
200 \\
200 \\
175\end{array}$ \\
\hline
\end{tabular}

was $49.8 \pm 14.0(\mathrm{SD})$ years. Thirty-three $(46.4$ per cent) patients were females; 17 had a family history of hypertension and 16 a family history of diabetes. Six patients had diabetes mellitus. Of
41 in whom the duration of hypertension could be determined, only 7 had had it for more than 10 years. The type of hypertension was diagnosed as labile in 9, fixed essential in 47 , renal in 12 (1

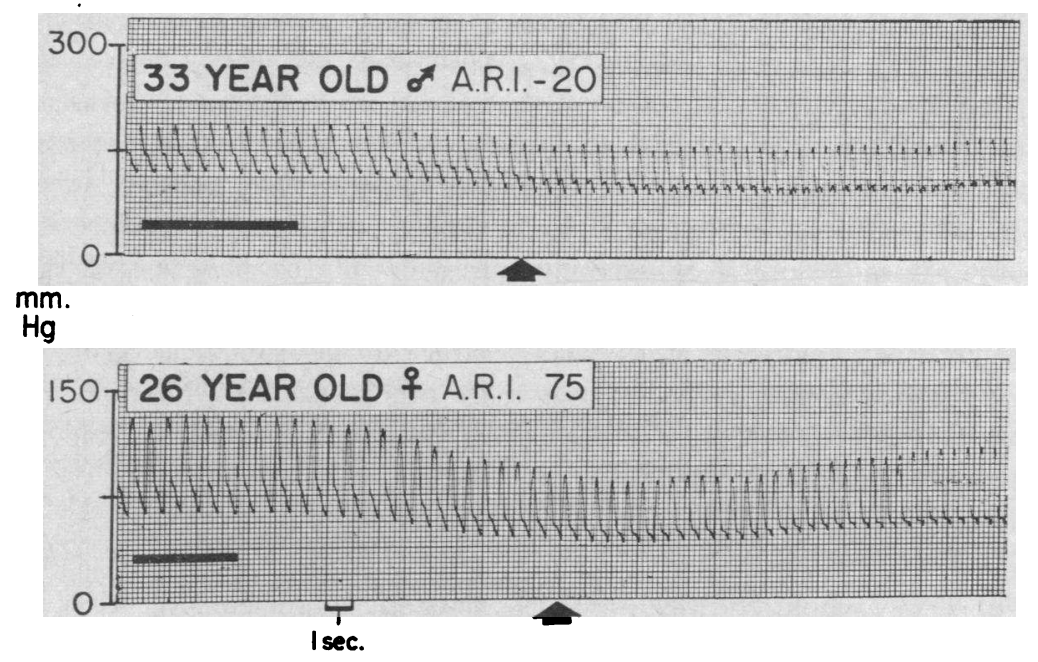

Fig. 1. Brachial arterial pRessures ReCorded before, DURING AND AFTER AMYL NITRITE INHALATION IN 2 subJECTS. The horizontal lines below the tracings indicate the time of inhalation of amyl nitrite. The vertical arrows indicate the onset of reflex tachycardia. When the change in pulse pressure is negligible (upper tracing) the arterial rigidity index (A.R.I.) is small $(-20)$. When the fall in pulse pressure is marked (lower tracing) the A.R.I. is high $(+75)$. 


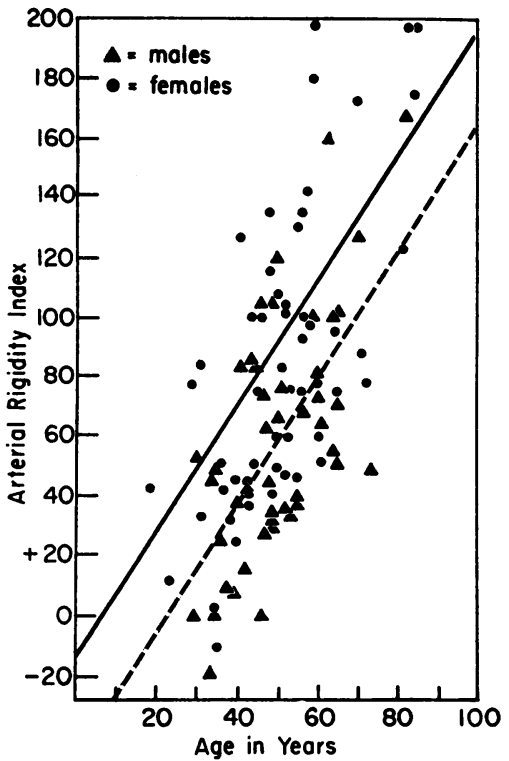

Fig. 2. Arterial Rigidity indices (ordinate) of 100 HYPERTENSIVE PATIENTS RANGING FROM 18 TO 84 YEARS OF AGE. The interrupted line represents the regression of this index on age in normal subjects; the solid line is the upper limit of normal (3). Seventy-one hypertensive patients had indices below the upper limit and 29 had prematurely elevated indices. The incidence of hypertensive females with premature arterial aging was high.

had Kimmelstiel-Wilson's syndrome), and undetermined in 3. The average diastolic pressure at the time of the test was $101.0 \pm 22.0 \mathrm{~mm} \mathrm{Hg}$ and the average pulse pressure was $82.9 \pm 27.0 \mathrm{~mm} \mathrm{Hg}$. There was roentgenographic evidence of tortuosity and calcification of the aorta in 9 patients, 6 of whom were over 60 years of age. Electrocardiographic evidence of left ventricular hypertrophy was present in 23 and grade III or IV eye-ground changes were found in 11 .

Twenty-nine hypertensive subjects with prematurely high rigidity indices. The average age of this group was $52.4 \pm 16.5$ (SD) years. Twenty (68.9 per cent) patients were females; 4 had a family history of hypertension and 7 had a family history of diabetes. Eleven patients had diabetes mellitus. Eleven of 18 in whom the duration of hypertension could be determined had been hypertensive for more than 10 years. There were 3 patients with labile hypertension, 17 with fixed hypertension and 8 with renal hypertension, 5 of whom were diabetics with Kimmelstiel-Wilson's syndrome. In one subject the type of hypertension had not been determined. The average dias- tolic pressure of this group was $89.7 \pm 18.3 \mathrm{~mm}$ $\mathrm{Hg}$ and the average pulse pressure was $99.4 \pm 26.7$ $\mathrm{mm} \mathrm{Hg}$. Tortuosity or calcification of the aorta was present in 11, 8 of whom were younger than 60 years of age. There was electrocardiographic evidence of left ventricular hypertrophy in 12 , and grade III or IV hypertensive retinopathy was found in 10 .

Comparison between the two groups. As shown in Table II, there were relatively more diabetics and patients with hypertension of more than 10 years' duration in the group with prematurely elevated indices. The incidence of females was higher also in this group and grade III or IV eyeground changes were more common as were other abnormalities seen with advanced arteriosclerosis, such as a wider pulse pressure, lower diastolic pressure and tortuosity of the aorta. There was no difference between the two groups in regard to age, type of hypertension, incidence of left ventricular hypertrophy and incidence of family history of hypertension or diabetes.

\section{DISCUSSION}

The results show that only 29 hypertensive patients had high rigidity indices for their own age and 71 had normal indices. It is apparent that premature aging of the arteries of hypertensive patients is not nearly as prevalent as was reported $(2,4)$. The main reason for this discrepancy lies in the interpretation of the results. Although the old hypertensive patients in our study had high rigidity indices, many were considered "normal" in view of the progressive increase of the index with age which we had demonstrated (3). This effect of physiological aging was not considered by others $(2,4)$ who reported that the majority of hypertensive patients had abnormally rigid arteries and postulated that the processes leading to rigidity of the large arteries were also associated with sclerosis of the peripheral vascular bed and diastolic hypertension. Our findings do not support this hypothesis, since the majority of patients in this study had normal rigidity indices for their age.

These results indicate that the hypertensive patients have no greater decrease in distensibility with stretch than do the normals with age, although they might indeed have less distensible ar- 
TABLE II

Comparison of clinical observations made on normotensive subjects, hypertensive patients with "normal rigidity indices" and hypertensive patients with "prematurely elevated indices"

\begin{tabular}{|c|c|c|c|c|c|}
\hline & \multirow{3}{*}{$\begin{array}{l}\text { Normotensive } \\
\text { subjects* } \\
\text { (A) }\end{array}$} & \multicolumn{2}{|c|}{ Hypertensive patients with } & & \\
\hline & & \multirow{2}{*}{$\underset{\substack{\text { Normal } \\
\text { indices }}}{\text { (B) }}$} & \multirow{2}{*}{$\begin{array}{l}\text { Prematurely } \\
\text { elevated } \\
\text { indices } \\
\text { (C) }\end{array}$} & \multicolumn{2}{|c|}{$\begin{array}{c}\text { Significance of difference ( } p \\
\text { values) between }\end{array}$} \\
\hline & & & & $A$ and $B$ & $B$ and $C$ \\
\hline No. of patients & 115 & 71 & 29 & & \\
\hline Average age (yrs) & 52.8 & 49.8 & 52.4 & $>0.2$ & $>0.4$ \\
\hline Sex, females & 42 & 33 & 20 & $>0.1$ & $<0.05$ \\
\hline \multicolumn{6}{|l|}{ Family history of } \\
\hline $\begin{array}{l}\text { Diabetes }(\%) \\
\text { Hypertension }\left(\mathcal{F}_{c}\right)\end{array}$ & 17.3 & $\begin{array}{l}22.5 \\
24.0\end{array}$ & $\begin{array}{l}24.1 \\
13.8\end{array}$ & $>0.2$ & $\begin{array}{l}>0.5 \\
>0.1\end{array}$ \\
\hline Incidence of diabetics $(\%)$ & & 8.5 & 38.0 & & $<0.001$ \\
\hline \multicolumn{6}{|l|}{ Duration of hypertension } \\
\hline $\begin{array}{l}>10 \text { yrs }(\%) \\
<10 \text { yrs }(\%) \\
\text { Undetermined }(\%)\end{array}$ & & $\begin{array}{r}9.8 \\
47.9 \\
42.3\end{array}$ & $\begin{array}{l}38.0 \\
24.0 \\
38.0\end{array}$ & & $\begin{array}{l}<0.001 \\
>0.05 \\
>0.7\end{array}$ \\
\hline \multicolumn{6}{|l|}{$\begin{array}{l}\text { Average arterial } \\
\text { pressures }(m m H g)\end{array}$} \\
\hline $\begin{array}{l}\text { Systolic } \\
\text { Diastolic } \\
\text { Pulse pressure }\end{array}$ & $\begin{array}{r}134.8 \\
69.8 \\
65.0\end{array}$ & $\begin{array}{r}183.9 \\
101.0 \\
82.9\end{array}$ & $\begin{array}{r}189.1 \\
89.7 \\
99.4\end{array}$ & $\begin{array}{l}<0.001 \\
<0.001 \\
<0.001\end{array}$ & $\begin{array}{l}>0.1 \\
<0.01 \\
<0.01\end{array}$ \\
\hline \multicolumn{6}{|l|}{ Type of hypertension } \\
\hline $\begin{array}{l}\text { Labile }(\%) \\
\text { Fixed }(\%) \\
\text { Renal }(\%) \\
\text { Undetermined }(\%)\end{array}$ & & $\begin{array}{r}12.6 \\
66.2 \\
16.9 \\
4.3\end{array}$ & $\begin{array}{r}10.3 \\
58.8 \\
27.5 \\
3.4\end{array}$ & & $\begin{array}{l}>0.7 \\
>0.4 \\
>0.5 \\
>0.8\end{array}$ \\
\hline $\begin{array}{l}\text { Retinopathy } \\
\text { (grade III-IV) }(c / c)\end{array}$ & & 15.5 & 34.5 & & $<0.05$ \\
\hline $\begin{array}{l}\text { Left ventricular } \\
\text { hypertrophy }(\%)\end{array}$ & & 32.4 & 41.3 & & $>0.1$ \\
\hline $\begin{array}{l}\text { Tortuosity or calcification } \\
\text { of aorta }(\%)\end{array}$ & 5.2 & 12.6 & 38.0 & $>0.05$ & $<0.01$ \\
\hline
\end{tabular}

* These observations were made in a previous study (3) in which the effect of age on the rigidity index was determined. These "normal" subjects were selected to satisfy certain criteria among which were the absence of a family history of diabetes, of grade III or IV retinopathy and of left ventricular hypertrophy.

teries. The pulse pressure and not the "rigidity index" would be the indication of distensibility, although it would have to be considered at comparable mean arterial blood pressures. Adamson and Doupe (7) showed that the central pulse wave velocity was increased in hypertensive patients, but only to the same extent as it would be in normals if their aortic mean pressure were equally raised; i.e., there was no indication of increased rigidity of the aorta in hypertension except in relation to the raised pressure. They concluded that defective arterial elasticity was not a factor in the pathogenesis of diastolic hypertension.
Although distensibility generally decreases with a rise in arterial pressure (8), the "rigidity index" probably remains constant over a fairly wide range of pressures (170 to $55 \mathrm{~mm} \mathrm{Hg}$ ) (3) beyond which it may either increase or decrease. This is because the index is directly related to the "curvature" and not the slope of arterial pressure-volume curves. However, when arterial mean pressure approximates $200 \mathrm{~mm} \mathrm{Hg}$ the distensibility curves of younger aortas bend more and more toward the pressure axis (9) and the index tends to increase, while the curves of older vessels lose their curvature and the index tends to decrease. The 
average mean pressures ${ }^{1}$ of the two groups of hypertensive patients at the time of the test were comparable (128.6 and $122.8 \mathrm{~mm} \mathrm{Hg}$ ), well below $200 \mathrm{~mm} \mathrm{Hg}$ and not very much higher than the average mean pressure of the normotensive group $(91.5 \mathrm{~mm} \mathrm{Hg})$. This made it possible to compare the indices of the hypertensive patients with those of "normal" subjects of the same age. Only three patients (nos. 15, 37 and 54) had diastolic pressures higher than $125 \mathrm{~mm} \mathrm{Hg}$, and consequently their low rigidity indices might have been caused by their high arterial mean pressures, which were over $180 \mathrm{~mm} \mathrm{Hg}$ in two and over 200 $\mathrm{mm} \mathrm{Hg}$ in the third.

The clinical features of the patients were examined carefully in an attempt to clarify the relation between hypertension and arteriosclerosis. Two observations were felt to be worthy of emphasis. The first was the higher incidence of diabetics in the group with premature arterial aging $(p<0.001)$. Diabetes has been shown to be associated with, or even preceded by, extensive vascular changes (10-13), while in essential hypertension, biopsy studies of various organs have not generally revealed morphological changes in the peripheral vessels $(14,15)$. It would seem more reasonable to attribute the premature arterial aging in the 11 diabetics in this group to their diabetic state rather than to their hypertension. A second important observation was the greater incidence of patients who had had hypertension for more than 10 years among those with prematurely elevated indices $(p<0.001)$. This relationship between the known duration of hypertension and aging of arteries suggests that the development of sclerotic vascular changes is a consequence rather than a cause of hypertension.

Autopsy studies have shown an association of hypertension with premature arteriosclerosis primarily in women (16). In this report, 20 of the 29 hypertensive patients with premature arterial aging were females. Master (17) has pointed out that three-fourths of females and only one-fourth of males with coronary occlusion had pre-existing hypertension. Why hypertension should be a prerequisite for the majority of females and only a minority of men who succumb to coronary occlusion is not clear. Whatever the reason, the

\footnotetext{
1 Mean arterial pressures were obtained by adding onethird of the pulse pressure to the diastolic pressure.
}

available evidence seems to favor the hypothesis that hypertension and arteriosclerosis, although interrelated, are two separate entities, their progress being influenced by independent factors.

Of the 29 hypertensive patients in the group with high indices, 7 had diabetes, 7 had had hypertension for more than 10 years, 4 had had both diabetes and hypertension for more than 10 years, 3 were over 80 years of age, 3 had a strong family history of diabetes and 1 had myxedema. Thus in 25 patients, premature arterial aging might have developed either as a complication of hypertension or in association with another disease independent of hypertension. In only 4 of the 100 hypertensive patients was there unexplained premature arterial aging.

\section{SUMMARY}

The purpose of this study was to re-examine the relationship between hypertension and aging of the arteries by means of the amyl nitrite test of arterial rigidity.

Our findings in 100 hypertensive patients revealed no evidence of premature arterial aging in 71 of them when they were compared with normal subjects of the same age.

The clinical features of the 29 hypertensive patients with abnormal rigidity indices suggested that arteriosclerosis and hypertension developed as two separate entities possibly potentiating each other. We found no evidence to suggest that hypertension might have been caused by arteriosclerosis extending to the peripheral vascular system. If structural changes in the peripheral vascular bed play a major role in the etiology of essential hypertension, they do not appear to be related to premature arterial aging as determined by this test.

\section{REFERENCES}

1. Roach, M. R., and Burton, A. C. The effect of age on the elasticity of human iliac arteries. Canad. J. Biochem. 1959, 37, 557.

2. Conway, J., and Smith, K. S. Aging of arteries in relation to hypertension. Circulation 1957, 15, 827.

3. Abboud, F. M., and Huston, J. H. The effects of aging and degenerative vascular disease on the measurement of arterial rigidity in man. J. clin. Invest. 1961, 40, 933.

4. Conway, J. Could hardening of arteries lead to diastolic hypertension? in Hypertension, Drug Ac- 
tion, Epidemiology and Hemodynamics, F. R. Skelton, Ed. New York, American Heart Association, 1958, vol. 7, p. 113.

5. Pickering, G. W. High Blood Pressure. London, J. and A. Churchill, 1955, pp. 181-183.

6. Snedecor, G. W. Statistical Methods Applied to Experiments in Agriculture and Biology, 5th ed. Ames, Iowa State College Press, 1956, pp. 18 and 45.

7. Adamson, J. P., and Doupe, J. The elasticity of the large arteries in hypertension. Canad. J. med. Sci. 1952, 30, 125.

8. Roach, M. R., and Burton, A. C. The reason for the shape of the distensibility curves of arteries. Canad. J. Biochem. 1957, 35, 681.

9. Hallock, P., and Benson, I. C. Studies on the elastic properties of human isolated aorta. J. clin. Invest. 1937, 16, 595.

10. Bell, E. T. A postmortem study of vascular disease in diabetes. Arch. Path. 1952, 53, 444.

11. Ricketts, H. T. The problem of degenerative vascular disease in diabetes. Amer. J. Med. 1955, 19, 933.
12. Dolger, $\mathrm{H}$. Clinical evaluation of vascular damage in diabetes mellitus. J. Amer. med. Ass. 1947, 134, 1289.

13. Dry, T. J., and Hines, E. A., Jr. The role of diabetes in the development of degenerative vascular disease, with special reference to the incidence of retinitis and peripheral neuritis. Ann. intern. Med. 1941, 14, 1893.

14. Kerohan, J. W., Anderson, E. W., and Keith, N. W. The arterioles in cases of hypertension. Arch. intern. Med. 1929, 44, 395.

15. Sommers, S. C., Relman, A. S., and Smithwick, R. H. Histologic studies of kidney biopsy specimens from patients with hypertension. Amer. J. Path. 1958, 34, 685.

16. Wilkins, R. H., Roberts, J. C., Jr., and Campbell, M. Autopsy studies in atherosclerosis. III. Distribution and severity of atherosclerosis in the presence of obesity, hypertension, nephrosclerosis, and rheumatic heart disease. Circulation 1959, 20, 527.

17. Master, A. M. Hypertension and coronary occlusion. Circulation 1953, 8, 170. 